\title{
Efektivitas Modul Keanekaragaman Hayati Berbasis Project Based Learning dalam Upaya Peningkatkan Hasil Belajar Kognitif Siswa SMA
}

\author{
Yuli Chasanah $^{1}$, Fatchur Rohman ${ }^{1}$, Siti Zubaidah ${ }^{1}$ \\ ${ }^{1}$ Pendidikan Biologi-Universitas Negeri Malang
}

\section{INFO ARTIKEL}

\section{Riwayat Artikel:}

Diterima: 26-02-2019

Disetujui: 23-04-2019

\section{Kata kunci:}

project based learning; biodiversity;

cognitive learning outcomes; project based learning;

keanekaragaman hayati; hasil belajar kognitif

\author{
Alamat Korespondensi: \\ Yuli Chasanah \\ Pendidikan Biologi \\ Universitas Negeri Malang \\ Jalan Semarang 5 Malang \\ E-mail: yuligibran@ rocketmail.com
}

\begin{abstract}
ABSTRAK
Abstract: This study aims to (1) test the effectiveness of modules developed using the ADDIE development method and (2) analyze the effectiveness of PjBL-based learning modules to improve students' cognitive learning outcomes through quasi-experimental results. The results of the study show that (1) the resulting module is valid and practical with an average validation value of $89.25 \%$, the meaning is very valid; (2) there is a difference in the learning outcomes of students using the PjBl-based module which is higher at 83.8 compared to the control class that does not use PjBL-based modules with learning presentation discussion methods of 76,7 .
\end{abstract}

\begin{abstract}
Abstrak: Penelitian ini bertujuan untuk (1) menguji efektivitas modul yang dikembangkan menggunakan metode pengembangan ADDIE dan (2) analisa efektivitas modul pembelajaran berbasis PjBL untuk meningkatkan hasil belajar kognitif siswa melalui hasil quasi eksperimen. Hasil penelitian menunjukkan bahwa (1) modul yang dihasilkan valid dan praktis dengan rerata nilai validasi sebesar $89,25 \%$ artinya sangat valid; (2) ada perbedaan hasil belajar siswa yang menggunakan modul berbasis $\mathrm{PjBl}$ lebih tinggi sebesar 83,8 dibandingkan dengan kelas kontrol yang tidak menggunakan modul berbasis PjBL dengan pembelajaran metode diskusi presentasi sebesar 76, 7 .
\end{abstract}

Pencapaian tujuan pendidikan nasional melalui kurikulum 2013 menekankan pendekatan saintifik yang berpusat pada siswa sehingga diharapkan siswa dapat memperoleh pengalaman yang berharga dalam setiap proses pembelajarannya (Moursund, 1999). Model pembelajaran saintifik bermacam-macam, diantaranya PjBL, yang menerapan pembelajaran sains hasil penelitian yang dapat meningkatkan hasil belajar dan pembelajaran yang efektif (Movahedzadeh, Patwell, Rieker, \& Gonzalez, 2012). Sudjana (2011) menjelaskan kemampuan siswa setelah menerima pengalaman belajar dinyatakan sebagai hasil belajar. Sopah (2000) menyatakan hasil belajar merupakan hasil kegiatan pembelajaran yang dimiliki oleh siswa. Pembelajaran berbasis proyek akan membutuhkan banyak keterampilan akademik siswa, seperti membaca, menulis, mengamati, menghitung, menganalisis untuk membentuk pemahaman konseptual yang berbeda setiap bidang kajian (Capraro, 2013).

Bahan ajar merupakan sumber belajar yang diterapkan dan diintegrasikan ke dalam proses belajar mengajar, sehingga pembelajaran lebih efektif (Chingos \& Whitehurst, 2012). Bahan ajar bermanfaat untuk memudahkan belajar bagi guru dan siswa (Darmadi, 2010), mencapai tujuan belajar (Tim Dosen, 2010), meningkatkan hasil belajar (Wahyudi, Hariyadi, \& Hariani, 2014) untuk meningkatkan pengetahuan dan pengalaman (Izzati, Hindarto, \& Pamelasari, 2013). Hasil observasi yang dilakukan di SMAN 1 Nglames Kabupaten Madiun dengan menggunakan kuisioner dan bahwa proses pembelajaran Biologi sudah menggunakan pendekatan saintifik, tetapi masih belum optimal. Selain itu, metode pembelajarannya masih dominan ceramah, diskusi dan presentasi berorientasi pencapaian hasil belajar kognitif saja dan belum melakukan proyek yang dapat memberdayakan potensi diri siswa. Hasil belajar kognitif siswa materi Keanekaragaman Hayati dan Klasifikasi masih rendah, dimana belum mencapai nilai KKM Biologi adalah 75. Hal ini terjadi karena siswa belum bisa sepenuhnya memahami materi yang diajarkan oleh pendidik dan mengaitkan pada kehidupan lingkungan sehari-hari siswa. Selain itu, bahan ajar yang di miliki sekolah sebagai media yang mendukung pembelajaran jumlahnya sangat terbatas. Hal ini terbukti bahwa siswa dipinjami buku sebagai bahan ajar hanya satu buah buku untuk setiap bangku dan siswa harus langsung mengembalikan ke perputakaan sekolah setelah selesai pembelajaran. Selain itu, sekolah tidak mengizinkan untuk penggunaan LKS dari penerbit yang kontennya tidak sesuai dengan kurikulum 2013 dikarenakan penulis LKS bukan hasil dari forum guru di MGMP Kabupaten Madiun. Oleh sebab itu, penulis ingin mengembangkan bahan ajar berupa modul yang bisa mendukung pembelajaran Kurikulum 2013. 
Modul adalah bahan ajar cetak yang dirancang sistematis agar dapat dipelajari siswa sendiri tanpa kehadiran pengajar secara langsung (Depdiknas, 2008). Menurut Kemdikbud (2017) pembelajaran Biologi sangat dekat dengan dunia siswa. Penggunaan modul dapat meningkatkan meningkatkan hasil belajar (Widyaningrum, Sarwanto, \& Karyanto, 2013). Modul dikatakan baik dan menarik jika memenuhi beberapa karakteristik berikut (Depdiknas, 2008) yaitu berisi lengkap materinya, ada petunjuk penggunaan, mudah dipelajari sendiri dan kekinian. Modul yang telah dibuat pada materi keanekaragaman hayati kemudian diimplementasikan ke dalam proses pembelajaran berbasis proyek (PjBL). PjBL dapat meningkatkan sikap dan hasil belajar Biologi siswa (Mahanal, Darmawan, Corebima, \& Zubaidah, 2010).

Penelitian ini bertujuan untuk (1) menguji efektivitas modul berbasis $P j B L$ pada materi keanekaragaman hayati dan klasifikasi SMA yang valid dan praktis menggunakan metode penelitian pengembangan ADDIE (Branch, 2009), dan (2) menganalisis efektivitas modul berbasis $P j B L$ untuk mengetahui perbedaann hasil bejar kognitif siswa melalui hasil quasi eksperimen.

\section{METODE}

Penelitian ini mengacu pada model penelitian \& pengembangan ADDIE (Branch, 2009) yang meliputi lima tahap, yaitu menganalisis, merancang, mengembangkan, menerapkan, dan mengevaluasi. Jenis penelitian ini adalah penelitian eksperimen semu. Siswa yang berpartisipasi dalam penelitian eksperimen semu terlebih dahulu diberikan formulir persetujuan. Penelitian eksperimen semu. Rancangan penelitian eksperimen semu menggunakan non-randomized pretes-postes kontrol grup design yang sebelum dan sesudah perlakuan dilakukan pengukuran terhadap kelompok perlakuan dan kelompok kontrol.

Penelitian ini dilakukan lima kali pertemuam pada semester ganjil tahun pelajaran 2018/2019 di SMA Negeri 1 Nglames.Variabel penelitian ini terdiri atas variabel bebas yaitu modul keanekaragaman hayati berbasis PjBL dan dan variabel terikat adalah hasil belajar kognitif. Populasi penelitian adalah seluruh siswa SMA Negeri 1 Nglames semester ganjil tahun pelajaran 2018/2019 dan sampel penelitian adalah siswa kelas X SMA Negeri 1 Nglames. Teknik pengambilan sampel dilakukan secara acak dengan cara dihitung berdasarkan kesetaraan nilai tes uji pendahuluan.

Instrumen penelitian eksperimen semu antara lain silabus, RPP, Modul keanekaragaman hayati berbasis PjBL, angket respon siswa terhadap modul dan pembelajaran, serta lembar observasi keterlaksanaan pembelajaran. Semua instrumen tersebut digunakan pada kelompok perlakuan. Adapun perangkat pembelajaran yang digunakan pada kelompok kontrol yaitu silabus, RPP, dan buku K13 yang dimiliki oleh guru dengan pembelajaran diskusi presentasi. Instrumen yang digunakan pada kedua kelompok (perlakuan dan kontrol) yaitu lembar soal pretes-postes hasil belajar kognitif. Jenis data penelitian yaitu data kualitatif dan data kuantitatif. Data kualitatif berupa komentar dan saran yang diberikan oleh para validator pada lembar validasi, komentar, dan saran yang diberikan oleh para siswa pada angket respon siswa, serta catatan observasi keterlaksanaan pembelajaran oleh observer.

Data kuantitatif berupa skor validasi oleh para validator, skor angket respons siswa, dan skor pretes-postes hasil belajar kognitif siswa. Data hasil validasi soal pretes-postes dan modul dianalisis dengan menggunakan analisa rerata skor. Data hasil angket respon siswa dianalisis dengan menggunakan analisis persentase. Data hasil pretes-postes hasil belajar kognitif siswa terlebih dahulu diuji normalitas dengan one-sample kolmogorov-Smirnov Test dan uji homogenitasnya menggunakan Levene's Test of equality of Error Variances. Bila data normal dan homogen selanjutnya dianalisis dengan analisis kovarian (anakova) satu jalur pada taraf signifikansi 5\%, bila data tidak normal dan homogen, maka data dianalisis dengan Quade's rank analysis of covariance. Keseluruhan analisis data tersebut dengan bantuan SPSS 22.0 for windows.

\section{HASIL}

Hasil validasi modul berdasarkan kriteria validasi disajikan pada tabel 1. Hasil validasi instrumen pembelajaran dalam penelitian ini disajikan pada tabel 2.

Tabel 1. Analisa Skor Validasi

\begin{tabular}{lcccccc}
\hline Validator & $\begin{array}{c}\text { Jumlah } \\
\text { Aspek }\end{array}$ & $\begin{array}{c}\text { Total Jumlah Skor } \\
\text { Jawaban Validasi }\end{array}$ & $\begin{array}{c}\text { Total jumlah } \\
\text { Skor Ideal }\end{array}$ & $\begin{array}{c}\mathbf{P} \\
(\mathbf{\%})\end{array}$ & Kategori & Keputusan Uji \\
\hline Ahli Modul & 28 & 105 & 112 & 93,75 & Layak digunakan & Tanpa Revisi \\
\hline Ahli Materi & 23 & 81 & 92 & 88,0 & Layak digunakan & Tanpa Revisi \\
\hline Ahli Pendidikan & 28 & 92 & 112 & 82,14 & Layak digunakan & Tanpa Revisi \\
\hline & Rata-rata Skor & & & 89,25 & Layak digunakan & Tanpa Revisi \\
\hline
\end{tabular}

Tabel 2. Rangkuman Hasil Validasi Perangat Pembelajaran

\begin{tabular}{lcl}
\hline Instrumen & Persentase $(\%)$ & Kriteria \\
\hline Silabus & 82,14 & Cukup valid, atau dapat digunakan namun perlu revisi kecil dengan revisi sedikit \\
\hline RPP & 80,36 & Cukup valid, atau dapat digunakan namun perlu revisi kecil dengan revisi sedikit \\
\hline Kisi-kisi soal & 86,36 & Sangat valid, atau dapat digunakan tanpa revisi \\
\hline Soal Pretest-posttest & 83,00 & Cukup valid, atau dapat digunakan namun perlu revisi kecil dengan revisi sedikit \\
\hline
\end{tabular}




\section{Data dan Analisis Uji Coba Pendahuluan}

Hasil uji coba pendahuluan terhadap 20 siswa yang sudah menempuh materi Keanekaragaman hayati tahun sebelumnya, yaitu kelas XI MIA dan XI IIS SMAN 1 Nglames sebagai kelas uji keterbacaan modul berbasis PjBL. Berikut ini respons siswa terhadap modul berbasis PjBL disajikan pada tabel 3 dan 4.

Tabel 3. Analisis Hasil Uji Coba Modul Tiap Aspek Respons Siswa

\begin{tabular}{clll}
\hline No & Aspek yang dinilai & Rata-Rata Skor (\%) & Kategori \\
\hline 1 & Kriteria Penyajian Fisik & 86,6 & Sangat Positif \\
\hline 2 & Kriteria Penyajian Konsep & 76 & Positif \\
\hline 3 & Kriteria Kemanfaatan & 86,6 & Sangat Positif \\
\hline 4 & Kriteria Kebahasaan & 75 & Positif \\
\hline 5 & Kriteria Kemahalan & 80 & Positif \\
\hline & Rata-rata & 80,84 & Positif \\
\hline
\end{tabular}

Tabel 4. Analisa Skor Validasi Uji Coba Pendahuluan oleh Siswa

\begin{tabular}{cccccr}
\hline Jumlah Aspek & $\begin{array}{c}\text { Total Jumlah Skor } \\
\text { Jawaban Validasi }\end{array}$ & $\begin{array}{c}\text { Total jumlah } \\
\text { Skor Ideal }\end{array}$ & $\begin{array}{c}\mathbf{P} \\
(\boldsymbol{\%})\end{array}$ & Kategori & Keputusan Uji \\
\hline 17 & 1506 & 1700 & 88,58 & Layak digunakan Predikat & Tidak Perlu Revisi \\
\hline
\end{tabular}

\section{Data dan Analisis Hasil Penelitian Eksperimen Semu}

Data dan analisis hasil implementasi dilakukan pada kelompok besar yaitu kelas X IIS 2 SMAN 1 Nglames Kab. Madiun. Berikut ini data hasil pretes-posttes nilai hasil belajar kognitif siswa yang menggunakan modul berbasis PjBL dan tidak menggunakan modul disajikan pada tabel 5. Berdasarkan hasil implementasi penggunaan modul berbasis PjBL dalam pembelajaran kelas eksperimen dibandingkan dengan kelas kontrol maka dapat diketahui keterlaksanaan sintak pembelajaran aktivitas guru dan siswa dapat dilihat pada tabel 6. Hasil analisis respons siswa terhadap penggunaan modul berbasis PjBL setelah porses kegiatan pembelajaran disajikan pada tabel 7.

Tabel 5. Rerata Pretest dan Posttest Hasil Belajar Siswa

\begin{tabular}{ccccccc}
\hline & \multicolumn{6}{c}{ Hasil Belajar Siswa } \\
\hline \multicolumn{2}{c}{ Kelas Eksperimen } & \multicolumn{2}{c}{ Kelas Kontrol } & \multicolumn{2}{c}{ Selisih } \\
\hline Pretest & Posttest & Pretest & Posttest & Pretest & Posttest \\
\hline Kognitif & 48,3 & 83,8 & 46 & 76,7 & 2,3 & 7,1 \\
\hline
\end{tabular}

Tabel 6. Keterlaksanaan Pembelajaran Aktivitas Guru dan Siswa

\begin{tabular}{|c|c|c|c|c|}
\hline \multirow[t]{2}{*}{ Kelas } & \multirow[t]{2}{*}{ Pertemuan } & \multicolumn{2}{|c|}{ Keterlaksanaan Pembelajarann (\%) } & \multirow[t]{2}{*}{ Rata-rata } \\
\hline & & Aktivitas Guru & Aktivitas Siswa & \\
\hline \multirow{5}{*}{ Eksperimen } & $\mathrm{Ke}-1$ & 84,6 & 92,3 & \multirow{5}{*}{88,7} \\
\hline & $\mathrm{Ke}-2$ & 87,5 & 87,5 & \\
\hline & $\mathrm{Ke}-3$ & 90 & 90 & \\
\hline & $\mathrm{Ke}-4$ & 88,5 & 84,6 & \\
\hline & $\mathrm{Ke}-5$ & 90,9 & 90,9 & \\
\hline \multirow{5}{*}{ Kontrol } & $\mathrm{Ke}-1$ & 90 & 83,3 & \multirow{5}{*}{86,6} \\
\hline & $\mathrm{Ke}-2$ & 85 & 88,8 & \\
\hline & $\mathrm{Ke}-3$ & 88 & 77,8 & \\
\hline & $\mathrm{Ke}-4$ & 85 & 86,1 & \\
\hline & $\mathrm{Ke}-5$ & 90 & 91,6 & \\
\hline
\end{tabular}

Tabel 7. Analisis Hasil Respons Siswa terhadap Penggunaan Modul untuk Setiap Aspek

\begin{tabular}{clcl}
\hline No & \multicolumn{1}{c}{ Aspek yang dinilai } & Rata-Rata Skor (\%) & \multicolumn{1}{c}{ Kategori } \\
\hline 1 & Kriteria Penyajian Fisik & 93,3 & Sangat positif \\
\hline 2 & Kriteria Penyajian Konsep & 80 & Positif \\
\hline 3 & Kriteria Kemanfaatan & 93,3 & Sangat positif \\
\hline 4 & Kriteria Kebahasaan & 75 & Positif \\
\hline 5 & Kriteria Kemahalan & 90 & Sangat positif \\
\hline & Rata-rata & 86,32 & Sangat positif \\
\hline
\end{tabular}




\section{PEMBAHASAN}

Produk penelitian yang dikembangkan adalah modul keanekaragaman hayati berbasis PjBL untuk siswa kelas X. Pengembangan ini dilakukan berdasarkan hasil analisis kebutuhan bahan ajar dan media belajar yang diperlukan untuk membantu meningkatkan hasil belajar kognitif siswa. Pemilihan modul dilakukan karena modul dilengkapi dengan petunjuk penggunaan secara sitematis (Mulyasa, 2009) dapat dipelajari siswa secara mandiri (Permendiknas, 2010) serta dapat mengeavluasi keberhasilan pembelajaran siswa (Santyasa, 2009).

Kriteria dan kualitas modul untuk belajar harus memperhatikan aspek-aspek yang ditetapkan oleh BSNP yaitu kelayakan materi, aspek bahasa dan gambar, serta aspek sajian tampilan (BNSP, 2014). Pada modul pembelajaran yang dikembangkan adalah modul keanekaragaman hayati berbasis Project Based Learning (PjBL) yang berisi materi keanekaragaman hayati dan klasifikasi. Bagian pendahuluan berisi tentang penjelasan umum mengenai modul dan indikator serta tujuan pembelajaran. Bagian kegiatan belajar berisi peta konsep uraian materi, rangkuman, tes atau soal evaluasi, kunci jawaban, dan umpan balik, sedangkan bagian penutup terdapat daftar pustaka, glosarium, dan daftar riwayat penulis.

Hasil validasi kelayakan modul yang telah dilakukan oleh ahli media, ahli materi, dan ahli pendidikan di sekolah diperoleh hasil rerata 89,25 dengan kriteria sangat valid dapat digunakan tanpa revisi. Sedangkan hasil validasi perangkat pembelajaran meliputi silabus 82,14\%, RPP 80,36\% dan soal pretes-posttes 83,36\% termasuk kategori cukup valid dengan revisi sedikit dan kisi-kisi soal hasil validasinya sebesar 86,36\% kriteria sangat valid tanpa revisi (Akbar, 2013) dengan beberapa saran yang diberikan validator sebagai perbaikan demi kesempurnaan pengembangan modul keanekaragaman hayati berbasis PjBL. Saran yang diberikan secara umum adalah tata penulisan yang salah, jenis font, gambar yang kurang banyak dan penulisan yang daftar rujukan yang tidak urut alfabetis. Dalam uji pendahuluan modul ini diperoleh hasil angket respons siswa sebesar 80,84 dengan kriteria positif (Riduwan, 2013). Prastowo (2015) menyebutkan fungsi modul sebagai (1) bahan ajar mandiri, (2) pengganti fungi pendidik, (3) relevansi, dan (4) rujukan siswa. Pada modul berbasis PjBL ini dilengkapi dengan petunjuk penggunaan modul sehingga bisa digunakan belajar siswa secara mandiri dan tidak bertemu langsung dengan guru, kegiatan proyek yang dilakukan disesuaikan dengan fenomena kehidupan sehari-hari siswa sehingga relevan dan juga materi yang lengkap dapat digunakan sebagai rujukan referensi sumber belajar siswa.

Sintaks dalam pembelajaran menggunakan modul keanekaragaman hayati berbasis Project Based Learning (PjBL). Afriana (2015) menjelaskan PjBL sebagai suatu pengajaran yang memecahkan masalah melalui proyek berbasis sains dan teknologi. Dalam pengembangan ini sintaks PjBL menurut Thomas (2000), meliputi mengawali dengan pertanyaan mendasar, mendesain perencanaan proyek, menyusun jadwal, memantau siswa dalam kemajuan proyek, menilai hasil, dan mengevaluasi pengalaman. Siswa dalam pembelajaran ini lebih aktif sendiri mengembangkan pengetahuannya dengan mendesain proyek yang bebas dipilih sesuai dengan materi keanekaragaman hayati dengan saran dan bimbingan guru serta diskusi masing-masing kelompok, sehingga siswa lebih banyak pengalamannya selama pembelajaran. Hal ini dapat dilihat pada saat melakukan proses mengerjakan proyek dengan berbagai masalah dan kendala yang harus dihadapi untuk menyelesaikan proyek sampai tuntas.

Berdasarkan keaktifan keterlaksaan aktivitas siswa dan guru dapat dilihat pada saat implementasi diantara kelas ekperimen yang menggunakan modul berbasi PjBl dengan kelas kontrol pembelajaran diskusi presentasi hasilnya berbeda. Keterlaksanaan aktivitas guru dan siswa di kelas yang menggunakan modul berbasis PjBL sebesar 88,7\% lebih tinggi dari pada kelas kontrol yang tidak menggunakan modul berbasis PjBL dengan metode pembelajaran diskusi presentasi hanya sebesar 86,6\%. Hal ini didukung oleh penelitian Iakovos (2011) model PjBL memungkinkan siswa untuk melakukan improvisasi, memberikan solusi dalam mengatasi permasalahan yang dihadapi, mencari alternatif agar dapat menyelesaikan suatu tugas, mengambil resiko, mengembangkan keterampilan berkomunikasi secara efektif, mengevaluasi kinerja diri, dan kelompoknya, dan bekerjasama dengan siswa lain. Menurut Kubiatko \& Vaculová (2011) PjBL adalah model pembelajaran yang berpusat pada siswa, mengandung solusi terhadap masalah yang diberikan oleh kelompok siswa, dan kerja siswa umumnya diakhiri dengan pembuatan produk.

Menurut Slameto (2010) hasil belajar dipengaruhi oleh beberapa faktor internal, seperti psikologis, kesehatan, minat, motivasi, IQ maupun eksternal, seperti guru, kurikulum, dan model pembelajaran. Dalam pembelajaran menggunakan modul Keanekaragaman Hayati Berbasis Project Based Learning (PjBL) memberikan pengaruh terhadap hasil belajar siswa. Siswa lebih berinteraksi secara langsung dengan yang diamati. Pembelajaran tersebut mampu menyerap informasi lebih banyak karena siswa mendapatkan lebih banyak kesempatan belajar. Siswa mencari informasi seluas-luasnya dan mengeksplorasi kemampuan dengan referensi yang tidak terbatas sesuai dengan topik yang dibahas untuk pelaksanaan proyek. Hasil belajar siswa yang menggunakan modul Keanekaragaman Hayati Berbasis PjBL lebih tinggi rata-ratanya sebesar 83,8 dibandingkan tanpa menggunakan modul dengan pembelajaran diskusi presentasi nilai rata-ratanya sebesar 76,7. Respons siswa terhadap modul setelah pembelajaran ada peningkatan lebih tinggi yaitu 91,02\% dengan rerata setiap aspek sebesar 86,32\% dibandingkan denga uji pendahuluan sebelum modul berbasis PjBL digunakan dalam pembelajaran di kelas sebesar 88,58\% dengan rerata setiap aspek sebesar $80,84 \%$. Model $P j B L$ memberikan tugas pembelajaran (seringkali dalam bentuk masalah berupa proyek) sebagai konteks dan stimulus untuk membangun pengetahuan (Tiantong \& Siksen, 2013).

Tugas pembelajaran yang autentik adalah jantung dari PjBL yaitu tugas tugas siswa dalam bekerja secara kolaboratif dengan teman dan gurunya untuk mengeksplor pertanyaan, menganalisis isu secara kritis (Roessingh \& Chambers, 2011), mendefinisikan masalah secara akurat, serta menghasilkan alternatif solusi beserta evaluasinya berdasarkan kriteria tertentu (Mioduser \& Betzer, 2008). Ketika siswa membagikan pengalaman mengenai pelaksanaan proyeknya, kegiatan tersebut sering 
membantu siswa untuk menambahkan ide milik temannya agar proyek lebih baik lagi kedepannya. Penelitian Dole, Bloom, \& Doss (2017) juga menyatakan bahwa pembelajaran PBL dan PjBl meningkatkan motivasi siswa untuk kerja mandiri selama proses pembelajaran.

Hasil analisis uji Anakova menunjukkan hasil belajar siswa memiliki signifikansi sebesar $0,000<0,05$. Data yang didapatkan menunjukkan bahwa nilai signifikansi lebih baik 0,05 sehingga hipotesis penelitian diterima. Apabila hipotesis penelitian diterima. Hal ini berarti ada pengaruh pembelajaran menggunakan modul keanekaragaman hayati berbasis $P j B L$ terhadap hasil belajar siswa. Perbedaan rerata pada nilai terkoreksi hasil belajar lebih tinggi pada kelas perlakuan yang menggunakan modul keanekaragaman hayati berbasis $P j B L$ daripada siswa dengan pembelajaran model diskusi dan presentasi. Hal tersebut menjelaskan bahwa hasil belajar siswa kelas eksperimen dibandingkan kelas kontrol lebih tinggi sebesar 3,856\%. Dapat disimpulkan bahwa hasil belajar siswa yang diberikan perlakuan dengan pembelajaran menggunakan modul keanekaragaman hayati berbasis $P j B L$ lebih baik dibandingkan dengan siswa yang diberikan perlakuan pembelajaran model diskusi dan presentasi.

Sesuai dengan penelitian Sahtoni, Suyatna, \& Manurung, (2017) bahwa modul PjBL dapat meningkatkan kreativitas siswa sebesar $80 \%$, menghasilkan produk yang baik sebesar 76,2\% dan respons positif siswa terhadap modul PjBL sebesar $92 \%$. Sejalan dengan penelitian Yamin, Permanasari, Redjeki, \& Sopandi (2017) bahwa PjBL dapat meningkatkan konsep siswa pada pelajaran Biologi materi pencemaran air dibandingkan dengan PBL. Demikian pula penelitian (Husamah \& Pantiwati, 2014) menyatakan Cooperative Learning STAD-PjBL meningkatkan motivasi dan kemampuan berpikir siswa yang berpengaruh terhadap hasil belajarnya.

\section{SIMPULAN}

Kesimpulan penelitian ini adalah modul keanekaragaman hayati berbasis PjBL layak dan praktis digunakan untuk pembelajaran Biologi. Perolehan nilai validator dari ahli materi, ahli media dan ahli pendidikan di sekolah diperoleh rerata nilai sebesar $89,25 \%$ artinya sangat valid dapat digunakan tanpa revisi. Berdasarkan hasil analisis anakova dinyatakan bahwa ada perbedaan hasil belajar siswa yang menggunakan modul berbasis PjBl lebih tinggi sebesar 83,8 dibandingkan dengan kelas kontrol yang tidak menggunakan modul berbasis PjBL dengan pembelajaran metode diskusi presentasi sebesar 76, 7.

Saran pengembangan produk selanjtnya sebagai berikut. Pertama, produk modul yang dikembangkan hanya pada materi keanekaragaman hayati dan klasifikasi sehingga pengembangan produk selanjutnya dapat mengembangkan modul berbasis PjBL dengan materi lain yang bisa membuat siwa lebih mudah belajar dan menarik meningkatkan minat dan motivasi belajar mencapai tujuan pembelajaran. Kedua, produk modul dalam penelitian ini hanya memiliki tujuan meningkatkan kemampuan hasil belajar kognitif siswa. Penelitian selanjutnya dapat mengembangkan produk yang mengembangkan kemampuan lainnya, seperti kemampuan literasi, sikap peduli lingkungan yang sesuai dengan kondisi siswa dan sekolah. Ketiga, pengembangan produk selanjutnya dapat mengembangkan modul berbasis PjBL untuk siswa dengan menggunakan model pembelajaran lainnya, seperti inkuiri terbimbing berbasis Problem Based Learning yang lebih inovatif dan dapat meningkatkan kompetensi siswa.

\section{DAFTAR RUJUKAN}

Akbar, S. (2015). Instrumen Perangkat Pembelajaran. Bandung: PT Remaja Rosdakarya

Branch, R. M. (2009). Instructional Design: The ADDIE Approach. Boston, MA: Springer US. https://doi.org/10.1007/978-0387-09506-6

Capraro, R. M. (Ed.). (2013). STEM Project-Based Learning: An Integrated Science, Technology, Engineering, and Mathematics (STEM) approach (2. ed). Rotterdam [u.a]: Sense Publ.

Darmadi, H. (2010). Kemampuan Dasar Mengajar. Bandung: Alfabeta.

Depdiknas. (2008). Panduan Pengembangan Bahan Ajar. Jakarta: Depdiknas.

Dole, S., Bloom, L., \& Doss, K. K. (2017). Engaged Learning: Impact of PBL and PjBL with Elementary and Middle Grade Students. Interdisciplinary Journal of Problem-Based Learning, 11(2). https://doi.org/10.7771/1541-5015.1685

Husamah., \& Pantiwati, Y. (2014). Cooperative Learning STAD-PjBL: Motivation, Thinking Skills, and Learning Outcomes of Biology Department Students. International Journalof Education Learning and Development, 2(1), 77-94.

Iakovos, T. (2011). Critical and Creative Thinking in the English Language Classroom. International Journal of Humanities and Social Science, 1(8), 82-86.

Insyasiska, D., Zubaidah, S., \& Susilo, H. (2015). Pengaruh Project Based Learning terhadap Motivasi Belajar, Kreativitas, Kemampuan Berpikir Kritis, dan Kemampuan Kognitif Siswa pada Pembelajaran Biologi. Jurnal Pendidikan Biologi, 7(1), 9-21.

Izzati, N., Hindarto, N., \& Pamelasari, S. D. (2013). Pengembangan Modul Tematik dan Inovatif Berkarakter pada Tema Pencemaran Lingkungan untuk Siswa Kelas VII SMP. Jurnal Pendidikan IPA Indonesia, 2(2), 183-188.

Kubiatko, M., \& Vaculová, I. (2011). Project-Based Learning: Characteristic and the Experiences with Application in the Science Subjects. Energy Education Science and Technology Part B: Social and Educational Studies, 3(1), 65-74. 
Mahanal, S., Darmawan, E., Corebima, A. D., \& Zubaidah, S. (2010). Pengaruh Pembelajaran Project Based Learning (PjBL) pada Materi Ekosistem terhadap Sikap dan Hasil Belajar Siswa SMAN 2 Malang. BIOEDUKASI (Jurnal Pendidikan Biologi), 1(1). https://doi.org/10.24127/bioedukasi.v1i1.179

Mioduser, D., \& Betzer, N. (2008). The Contribution of Project-Based-Learning to High-Achievers' Acquisition of Technological Knowledge and Skills. International Journal of Technology and Design Education, 18(1), 59-77. https://doi.org/10.1007/s10798-006-9010-4

Moursund, D. G. (1999). Project-Based Learning using Information Technology. Eugene, OR: International Society for Technology in Education.

Movahedzadeh, F., Patwell, R., Rieker, J. E., \& Gonzalez, T. (2012). Project-Based Learning to Promote Effective Learning in Biotechnology Courses. Education Research International, 2012, 1-8. https://doi.org/10.1155/2012/536024

Mulyasa, H. E. (2013). Pengembangan dan Implementasi Kurikulum 2013. Bandung: PT Remaja Rosdakarya.

Permendiknas. (2010). Peraturan Manteri Pendidikan Nasional Nomor 35 Tahun 2010 tentang Petunjuk Teknis Pelaksanaan Jabatan Fungsional Guru dan Angka Kreditnya.

Prastowo, A. (2012). Panduan Kreatif Membuat Bahan Ajar Inovatif (3rd ed.). Yogyakarta: Diva Press.

Riduwan. (2013). Skala Pengukuran Variabel-Variabel Penelitian. Bandung: Alfabeta.

Roessingh, H., \& Chambers, W. (2011). Project-Based Learning and Pedagogy in Teacher Preparation: Staking Out the Theoretical Mid-Ground. International Journal of Teaching and Learning in Higher Education, 23(1), 60-71.

Sahtoni, S., Suyatna, A., \& Manurung, P. (2017). Implementation of Student's Worksheet Based on Project Based Learning (pjbl) to Foster Student's Creativity. International Journal of Science and Applied Science: Conference Series, $2(1), 329$. https://doi.org/10.20961/ijsascs.v2i1.16738

Santyasa, I. W. (2009). Metode Penelitian Pengembangan dan Teori Pengembangan Modul. Makalah disajikan dalam Pelatihan bagi para Guru TK, SD, SMP, SMA, dan SMK di Kecamatan Nusa Penida Kabupaten Klungkung, 12-14 Januari 2009.

Slameto. (2010). Belajar dan Faktor-faktor yang Memengaruhinya. Jakarta: Rineka Cipta.

Sudjana, N. (2011). Penilaian Hasil Belajar Mengajar. Bandung: Remaja Rosdakarya.

Tiantong, M., \& Siksen, S. (2013). The Online Project-based Learning Model Based on Student's Multiple Intelligence. International Journal of Humanities and Social Science, 3(7), 204-211.

Widyaningrum, R., Sarwanto, S., \& Karyanto, P. (2013). Pengembangan Modul Berorientasi POE (Predict, Observe, Explain) Berwawasan Lingkungan pada Materi Pencemaran untuk Meningkatkan Hasil Belajar Siswa. Bioedukasi: Jurnal Pendidikan Biologi, 6(1), 100-117. https://doi.org/10.20961/bioedukasi-uns.v6i1.3920

Yamin, Y., Permanasari, A., Redjeki, S., \& Sopandi, W. (2017). Application of Model Project Based Learning on Integrated Science in Water Pollution. Journal of Physics: Conference Series, 895, 012153. https://doi.org/10.1088/1742$6596 / 895 / 1 / 012153$ 